\title{
Beim Bettsport purzeln die Pfunde
}

\begin{abstract}
Wenn es mit dem Abnehmen so gar nicht klappen will, empfehle ich meinen Patienten gerne eine App, in der man sowohl seine Mahlzeiten als auch seine sportlichen Aktivitäten eingibt. Die App rechnet aus, wie viele Kalorien man aufnimmt und verbraucht.

Eine meiner kräftigen Patientinnen war allerdings unzufrieden mit der App.
\end{abstract}

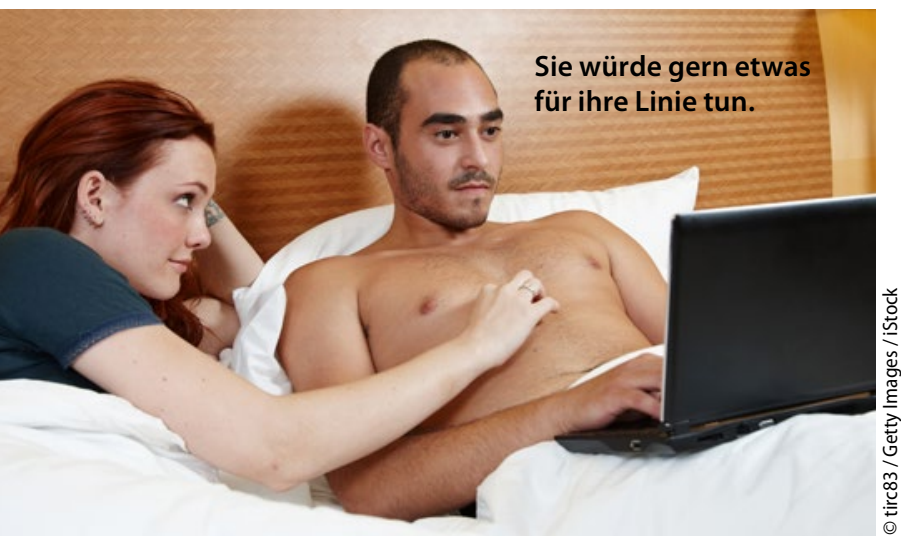

Sie beklagte sich darüber, dass sie weniger Kalorien aufnähme, als sie verbrauchte - aber dennoch kein Gewicht verlöre. „Sie können sich meine Aufzeichnungen gern mal ansehen“, sagte sie, und das tat ich auch. Schnell zeigte sich, dass sie zu wenig Gesundes und zu viel Süßes aß. Aber irgendetwas stimmte mit den Kalorien einfach nicht.

Ich scrollte zum Training, und da stach es mir ins Auge: „50 Minuten Sex $=657$ Kalorien" stand da. Beim schnellen Weiterblättern sah ich, dass die junge Dame sich offenbar eines intensiven Sexuallebens erfreute. Fast täglich hatte sie diese Kalorienzahl als „Training“ eingetragen.

„Selbst, wenn Sie sehr aktiv sind“, sagte ich vorsichtig, „würde ich Sex vielleicht mit 200 Kalorien pro Stunde ansetzen.“ Sie war überrascht und schwor, dass der elektronische Fitness-Helfer ihr die deutlich höhere Kalorienzahl vorgeschlagen hatte. Von nun an wollte sie aber mit meinen Zahlen arbeiten.

$\mathrm{Zu}$ Hause öffnete ich sofort die App, die ich auch auf meinem Telefon benutze, auch wenn ich selbst noch nie auf die Idee gekommen war, diese „Leibesübungen“ als Training einzutragen. Schnell fand ich die vorgegebenen Verbrauchszahlen: Für Sex waren 180 Kalorien pro Stunde angegeben. Für das Vorspiel waren es 20 Kalorien. Letzteres gab mir einiges zu philosophieren, ersteres fand ich nachvollziehbar.

Wie die Patientin auf ihren Kalorienverbrauch gekommen war, blieb mir indes schleierhaft. Vielleicht hatte sie stattdessen Thaiboxen oder Triathlon eingetragen.

Dr. Frauke Höllering, Arnsberg

\section{Der junge Wunderheiler richtet mal eben den Arm}

Als ich junger Assistenzarzt in der Chirurgie war, erschien eines Sonntags ein älterer Herr, der nach einem Sturz seinen linken Arm nicht mehr bewegen konnte. Es sprach nicht viel für einen Knochenbruch, aber einiges für eine Luxation des Schultergelenks.

Bevor er zum Röntgen ging, fasste ich einmal kurz auf die Stelle des Hauptschmerzes. Niemand war erstaunter als ich selbst, als der Patient mich in den höchsten Tönen lobte und sich bedank- te: „Herr Doktor, sie haben magische Hände. Es ist wieder gut, nichts tut mehr weh. Schauen Sie mal, ich kann den Arm wieder bewegen!“ Es kann nur so gewesen sein, dass der Arm „fast“ ausgerenkt war - und durch mein Anfassen rein zufällig wieder in die richtige Position zurück gerutscht ist. Im trotzdem noch durchgeführten Röntgenbild sahen wir regelrechte Verhältnisse. So kommt man zu unverdientem Ruhm.

Dr. Henrich Malz, Vlotho

\section{Chefarzt, Kellner - wo ist da schon der Unterschied?}

Seine Ehefrau hatte an der Bushaltestelle ein Plakat gesehen, auf dem Paul Breitner nebst Gattin für die Darmspiegelung warben. Das hatte sie überzeugt. Nicht begeistert, aber tapfer ging mein Patient also zum Chefarzt unseres benachbarten Hospitals.

Als er aus der Narkose erwachte, fragte inn der Doktor, ob er noch einen Wunsch hätte. Noch voll daneben gab er zur Antwort: „Ja, ich hätte gerne einen Cappuccino!" "Sehr wohl, der Herr!", sprach der Chefarzt. „Ich bin ja hier der Oberkellner." Seinen Cappuccino bekam der Patient.

Dr. Luise Hess, Darmstadt 